\title{
Quantification of glucuronidated and sulfated steroids in human urine by ultra-high pressure liquid chromatography quadrupole time-of-flight mass spectrometry
}

\author{
Flavia Badoud • Elia Grata • Julien Boccard • \\ Davy Guillarme • Jean-Luc Veuthey $\cdot$ Serge Rudaz • \\ Martial Saugy
}

Received: 17 December 2010 /Revised: 3 February 2011 / Accepted: 4 February 2011 /Published online: 6 March 2011

(C) Springer-Verlag 2011

\begin{abstract}
The urinary steroid profile is constituted by anabolic androgenic steroids, including testosterone and its relatives, that are extensively metabolized into phase II sulfated or glucuronidated steroids. The use of liquid chromatography coupled to mass spectrometry (LC-MS) is an issue for the direct analysis of conjugated steroids, which can be used as urinary markers of exogenous steroid administration in doping analysis, without hydrolysis of the conjugated moiety. In this study, a sensitive and selective ultra high-pressure liquid chromatography coupled to quadrupole time-of-flight mass spectrometer (UHPLCQTOF-MS) method was developed to quantify major urinary metabolites simultaneously after testosterone intake. The sample preparation of the urine $(1 \mathrm{~mL})$ was performed by solid-phase extraction on Oasis HLB sorbent using a 96-well plate format. The conjugated steroids were analyzed by UHPLC-QTOF-MS ${ }^{\mathrm{E}}$ with a single-gradient elution of $36 \mathrm{~min}$ (including re-equilibration time) in the negative electrospray ionization mode. $\mathrm{MS}^{\mathrm{E}}$ analysis involved
\end{abstract}

F. Badoud · E. Grata $\cdot$ M. Saugy

Swiss Laboratory for Doping Analyses,

University Center of Legal Medicine, Geneva and Lausanne,

Chemin des Croisettes 22,

1066 Epalinges, Switzerland

F. Badoud · J. Boccard · D. Guillarme $\cdot$ J.-L. Veuthey $\cdot$ S. Rudaz

School of Pharmaceutical Sciences, University of Geneva,

University of Lausanne,

Bvd d'Yvoy 20,

1211 Geneva 4, Switzerland

F. Badoud $\cdot$ E. Grata $\cdot$ J. Boccard $\cdot$ D. Guillarme $\cdot$ J.-L. Veuthey

S. Rudaz $\cdot$ M. Saugy $(\bowtie)$

Swiss Centre for Applied Human Toxicology, CMU,

1211 Geneva 4, Switzerland

e-mail: martial.saugy@chuv.ch parallel alternating acquisitions of both low- and highcollision energy functions. The method was validated and applied to samples collected from a clinical study performed with a group of healthy human volunteers who had taken testosterone, which were compared with samples from a placebo group. Quantitative results were also compared to GC-MS and LC-MS/MS measurements, and the correlations between data were found appropriate. The acquisition of full mass spectra over the entire mass range with QTOF mass analyzers gives promise of the opportunity to extend the steroid profile to a higher number of conjugated steroids.

Keywords Testosterone - Steroids · Glucuronide and sulfate conjugates · Ultra high-pressure liquid chromatography · Quadrupole time-of-flight $\cdot$ Quantification $\cdot \mathrm{MS}^{\mathrm{E}}$

\section{Introduction}

Anabolic androgenic steroids (AAS) are endogenous compounds that constitute the steroid profile, which is mainly based on testosterone (T), its epimer (epitestosterone (E)), its major metabolites (androsterone (A), etiocholanolone (Etio), $5 \alpha$-androstan- $3 \alpha, 17 \beta$-diol ( $5 \alpha$ Adiol) and $5 \beta$-androstan- $3 \alpha$, $17 \beta$-diol (5ßAdiol)), and its precursor (dehydroepiandrosterone (DHEA)) excreted as phase II glucuro- or sulfoconjugated compounds in urine. The steroid profile provides information on the metabolism pathway of androgenic compounds and is essential to identify inborn errors and for the diagnosis of diseases related to steroid secretion [1,2]. These compounds are widely used as doping agents in sports and are not restricted to professionals, which becomes a public health concern [3] because steroid administration is used for 
enhancing physical appearance more than it is used for enhancing performance.

For doping control analysis, criteria have been established in the World Anti-Doping Agency (WADA) Prohibited List to highlight the alteration of the steroid profile by exogenous administration of $\mathrm{T}$ or its precursors. Indeed, intake of natural anabolic steroids is known to raise the urinary concentration of the parent steroid and its metabolites [4]. Therefore, some parameters, including a testosterone over epitestosterone ratio $(\mathrm{T} / \mathrm{E})$ greater than or equal to 4 , are suspicious of exogenous $\mathrm{T}$ intake and necessitates further confirmation analysis by $\mathrm{GC}$ combustion isotope ratio mass spectrometry (GC-C-IRMS) [5].

The detection of AAS by gas chromatography coupled to mass spectrometry (GC-MS) has been extensively reported and reviewed $[1,2,6,7]$. GC-MS methods are sensitive and robust, but they suffer from time-consuming sample preparation, including hydrolysis and derivatization steps. Moreover, this procedure does not provide complete phase II information on the steroid profile. Thus, development of liquid chromatography-mass spectrometry (LC-MS) methods that allow for the direct analysis of steroid conjugates is of great interest for studying AAS metabolism. To date, the detection of intact glucuronidated and/or sulfated steroids has been reported by LC-MS/MS [8-14]. Furthermore, ultra high-pressure liquid chromatography (UHPLC) was recently used for metabolomics or profiling approaches for anabolic steroids in urine $[15,16]$. This technique is of huge interest for resolving conjugated AAS, as it allows enhancement of efficiency with columns packed with small particles (sub-2 $\mu \mathrm{m}$ ), which provide high peak capacity within a reasonable analysis time [17].

Mass spectrometry has also improved AAS detection, thanks to its sensitivity in detecting low amounts of substance in complex matrices [18]. Additionally, the improvement of time-of-flight or quadrupole time-of-flight mass spectrometry (TOF-MS or QTOF-MS) in terms of sensitivity and resolution has allowed its application in doping control analysis for accurate and sensitive full mass range acquisition [19-21]. QTOF-MS achieves accurate mass determination on molecular and fragment ions, giving structural information on unknown compounds or highlighting undiscovered metabolites [22, 23]. This technique is therefore popular for drug metabolism studies that require identification of new entities [24]. Moreover, QTOF-MS coupled to a $\mathrm{MS}^{\mathrm{E}}$ acquisition provides parent and fragment mass information in a single run, which is useful for targeted and metabolite profiling studies [25]. Finally, although TOF or QTOF mass analyzers could present a limited dynamic range, some authors have reported their use for quantitative evaluation [26-28].

In this study, the quantitative capabilities of QTOF-MS are explored for the determination of the steroid profile. A
UHPLC-QTOF-MS ${ }^{\mathrm{E}}$ approach is presented for the simultaneous quantification of 11 endogenous sulfo- or glucuroconjugated steroids in human urine.

\section{Experimental}

\section{Chemicals and reagents}

All commercially available standards for AAS in glucuroand sulfoconjugated form were acquired. 4-Androsten- $17 \beta$ ol-3-one sulfate sodium salt (testosterone sulfate (TS)), 4 -androsten-17 $\alpha$-ol-3-one sulfate sodium salt (epitestosterone sulfate (ES)), $5 \beta$-androstan- $3 \alpha$-ol-17-one sulfate sodium salt (etiocholanolone sulfate (EtioS)), 5-androsten-3 $\beta$-ol17-one sulfate sodium salt (dehydroepiandrosterone sulfate (DHEAS)), 4-androsten-17 $\beta$-ol-3-one glucosiduronate (testosterone glucuronide (TG)) 4-androsten-17 $\alpha$-ol-3-one glucosiduronate (epitestosterone glucuronide (EG)), $5 \beta$ androstan-3 $\alpha$-ol-17-one glucosiduronate (etiocholanolone glucuronide (EtioG)), 5 -androsten-3 $\beta$-ol-17-one glucosiduronate (dehydroepiandrosterone glucuronide (DHEAG)), and $5 \alpha$-androstan- $3 \beta, 17 \beta$-diol-3-glucosiduronate $(\alpha$-diol-3glucuronide $(5 \alpha \beta \beta$-AdiolG) $)$ were purchased from Steraloids (Newport, RI, USA). $5 \alpha$-Androstan-3 $\alpha$-ol-17-one sulfate triethylammonium salt (androsterone sulfate (AS)), $5 \alpha$ androstan-3 $\alpha$-ol-17-one-3 $\alpha$-d-glucuronide (androsterone glucuronide (AG)), $\left[16,16,17 \alpha^{-}{ }^{2} \mathrm{H}_{3}\right]$ androst-4-en-17 $\alpha$-ol-3one sulfate triethylammonium salt (TS- $\left.d_{3}\right),\left[16,16,17 \beta-{ }^{2} \mathrm{H}_{3}\right]$ androst-4-en-17 $\beta$-ol-3-one sulfate triethylammonium salt (ES- $\left.d_{3}\right),\left[2,2,3 \beta, 4,4-{ }^{2} \mathrm{H}_{5}\right] 5 \beta$-androstan- $3 \alpha$-ol-17-one sulfate triethylammonium salt (EtioS- $\left.d_{5}\right),\left[2,2,4,4-{ }^{2} \mathrm{H}_{4}\right] 5 \alpha$-androstan-3 $\alpha$-ol-17-one sulfate triethylammonium salt (AS- $d_{4}$ ), $\left[16,16,17 \alpha-{ }^{2} \mathrm{H}_{3}\right]$ androst-4-en-17 $\beta$-ol-3-one glucuronide (TG- $\left.d_{3}\right),\left[16,16,17 \alpha_{-}{ }^{2} \mathrm{H}_{3}\right]$ androst-4-en-17 $\alpha$-ol-3-one glucuronide (EG- $\left.d_{3}\right)$, and $\left[2,2,4,4-{ }^{2} \mathrm{H}_{4}\right] 5 \alpha$-androstan- $3 \alpha$-ol-17-one glucuronide $\left(\mathrm{AG}-d_{4}\right)$ were purchased from the Australian Government National Measurement Institute (Pymble, Australia). Ultra pure water was provided by a Milli-Q system from Millipore (Bedford, MA, USA), and ULC-MS quality of water and acetonitrile was obtained from Biosolve (Chemie Brunschwig, Basel, Switzerland). Formic acid and ammonium hydroxide were purchased from Fluka (Buchs, Switzerland). Methanol was supplied by Merck (Darmstadt, Germany).

\section{Solutions}

Stock standard solutions were obtained in methanol at a concentration of $1 \mathrm{mg} / \mathrm{mL}$ for all standards, except for AS and EtioS which were stocked at a concentration of $2 \mathrm{mg} / \mathrm{mL}$.

Stock internal standards (I.S.s) solutions were obtained in methanol at a concentration of $100 \mu \mathrm{g} / \mathrm{mL}$, except for AG- $d 4$, which was stocked at $1 \mathrm{mg} / \mathrm{mL}$. The working I.S.s 
solution was obtained by spiking $100 \mu \mathrm{L}$ of the TS- $d 3$ and ES- $d 3$ stock solutions; $200 \mu \mathrm{L}$ of TG- $d 3$, EG- $d 3$, and AG$d 4$; and $500 \mu \mathrm{L}$ of AS- $d 4$ and Etios- $d 5$ into $10 \mathrm{~mL}$ of methanol. Solutions were stored at $-20{ }^{\circ} \mathrm{C}$ in glass tubes fitted with PTFE caps.

\section{Sample preparation}

A solid-phase extraction (SPE) on Oasis HLB (Waters, Milford, MA, USA) cartridges ( $30 \mathrm{mg}, 30 \mu \mathrm{m}$ particle size) was developed for a 96-well plate format to extract selectively glucuro- and sulfoconjugated AAS from urine samples.

The loading solution was prepared by diluting $1 \mathrm{~mL}$ of urine with $1 \mathrm{~mL}$ of $2 \%$ formic acid solution spiked with $10 \mu \mathrm{L}$ of the I.S.s working solution. The extraction protocol was performed as follows: cartridges were first conditioned with $500 \mu \mathrm{L}$ of methanol and equilibrated with $500 \mu \mathrm{L}$ of a solution containing $2 \%$ formic acid. The loading solution was added on the sorbents, and two washing steps followed. Cartridges were first washed with $1 \mathrm{~mL}$ of a $2 \%$ formic acid solution and were then washed with $1 \mathrm{~mL}$ of a $5 \%$ ammonium hydroxide/methanol $(90 \% / 10 \%, v / v)$ solution. The elution step consisted of $500 \mu \mathrm{L}$ of $40 \%$ methanol $/ 60 \%$ water. Eluates were transferred into conical glass tubes, and the wells were washed three times with $500 \mu \mathrm{L}$ of methanol. The solvent was evaporated to dryness under a gentle air stream, and the dry residue was reconstituted with $100 \mu \mathrm{L}$ of a mixture of $30 \%$ acetonitrile $/ 70 \%$ water.

\section{UHPLC conditions}

Separations were performed on an Acquity UPLC system (Waters) with Acquity UPLC columns (BEH $\mathrm{C}_{18} 150 \times$ $2.1 \mathrm{~mm}, 1.7 \mu \mathrm{m})$ at $25^{\circ} \mathrm{C}$ and $300 \mu \mathrm{L} / \mathrm{min}$. A Van Guard (Waters) pre-column $\left(\mathrm{BEH} \mathrm{C}_{18}, 5 \times 2.1 \mathrm{~mm}, 1.7 \mu \mathrm{m}\right)$ was placed prior to the column. The mobile phase was (A) $0.1 \%$ formic acid in water and (B) $0.1 \%$ formic acid in acetonitrile. The gradient started linearly from 5\% to $37 \%$ B over $25 \mathrm{~min}$, followed by a washing step to $95 \%$ B for $3 \mathrm{~min}$; the system was then re-equilibrated for $8 \mathrm{~min}$. The injection volume was fixed at $20 \mu \mathrm{L}$ in the full loop mode, and samples were maintained at $4{ }^{\circ} \mathrm{C}$ in the autosampler.

\section{QTOF-MS $^{\mathrm{E}}$ parameters}

Analyses were performed using a Micromass-Q-Tof Premier mass spectrometer (Waters) equipped with an electrospray ionization (ESI) source operated in the negative mode. MS operating conditions were set as follows: the desolvation gas flow was $800 \mathrm{~L} / \mathrm{h}$ with a temperature of $360^{\circ} \mathrm{C}$, the capillary voltage was defined as $2.4 \mathrm{kV}$, and the cone voltage was kept constant at $50 \mathrm{~V}$. The micro-channel plates (MCPs) were operated at $1,750 \mathrm{~V}$ with $3.6 \mathrm{GHz}$ time-to-digital converters (TDC), the source temperature was $120^{\circ} \mathrm{C}$, and the cone gas flow and the collision gas flow were set to $10 \mathrm{~L} / \mathrm{h}$ and $0.25 \mathrm{~mL} / \mathrm{min}$, respectively.

The QTOF mass spectrometer was operated in wide-pass quadrupole mode with a low collision energy set at $5 \mathrm{eV}$ in the first function, and a collision energy ramp from 5 to $70 \mathrm{eV}$ was applied in the second function $\left(\mathrm{MS}^{\mathrm{E}}\right.$ mode). Data were collected in V-optics centroid mode over ranges of $m / z 95-1,000$ in the first function and $m / z 50-1,000$ in the second function with a scan time of $0.2 \mathrm{~s}$ and an interscan delay of $0.02 \mathrm{~s}$. For the dynamic range enhancement (DRE) lockmass, a $2-\mathrm{ng} / \mathrm{mL}$ solution of leucine-enkephalin (Sigma-Aldrich, Buchs, Switzerland) was infused through the Lock Spray probe at $5 \mu \mathrm{L} / \mathrm{min}$.

\section{Software}

Data acquisition, data handling, and instrument control were performed using MassLynx Software (Waters).

\section{Validation}

\section{Guidelines}

Experiments were conducted in compliance with the Internal Standards for Laboratories (ISL) of the World Anti-Doping Code [29]. Detailed procedures were found in the "Identification method validation" section from the International Conference for Harmonization (ICH) guidelines [30]. The US Food and Drug Administration (FDA) guidelines [31] and the Third American Association of Pharmaceutical Scientists (AAPS)/FDA Bioanalytical Workshop in 2006 [32] were consulted for the assay of stability and carry-over, respectively. Finally, the last concept paper regarding bioanalysis from the European Medicines Agency (EMEA) [33] was referred for the requirement of matrix effect study in case of LC-MS methods.

\section{Selectivity}

Because human urine samples may contain endogenous AAS, negative urine samples from children younger than 3 years old (one urine sample from a boy and two urine samples from girls) were collected for development and validation purpose because they contained a lower amount of steroids [34]. The levels of endogenous steroids ( $5 \alpha \beta \beta$ AdiolG, TG, EG, DHEAG, AG, EtioG, TS, ES, DHEAS, AS, and EtioS) were estimated with the negative children's urine samples and were considered sufficiently low to be used for calibration and validation procedures (data not 
shown). UHPLC-QTOF-MS ${ }^{\mathrm{E}}$ chromatograms were visually examined and compared for potential interferences with the negative urine samples. The negative urine samples were also spiked with the working I.S.s solution to ensure the lack of selectivity towards the I.S.s themselves.

\section{Matrix effects}

Matrix effects were determined using a method described by Matuszewski et al. [35] and revisited by Marchi et al. [36]. Assays were performed at low and high concentrations for each compound ( 5 and $200 \mathrm{ng} / \mathrm{mL}$ for $5 \alpha \beta \beta$-AdiolG; 2 and $100 \mathrm{ng} / \mathrm{mL}$ for TS and ES; 10 and $200 \mathrm{ng} / \mathrm{mL}$ for TG, EG, and DHEAG; 500 and 2,000 ng/mL for DHEAS, AS, and EtioS; and 1,000 and 4,000 ng/mL for AG and EtioG). Four samples were prepared for the exhaustive classification of phenomena that estimated the global process efficiency (PE), the matrix influence on the MS signal (ME; including ionization perturbation), the extraction recovery (RE), and the extraction yield (EY). Indeed, PE was expressed as a percentage of the peak areas of the analytes spiked in the matrix to the areas of the analytes in a neat solution. The ME was evaluated by comparing the peak areas of the standards spiked in the extracted urine to that of the neat standard solution. The RE was obtained by calculating the ratio of the peak areas of the analytes spiked in the urine to the analytes reconstituted in a post-extracted matrix. Finally, the EY was expressed as the ratio of the peak areas of the standard extracted in water to that of the neat solution.

\section{Quantitative analysis}

Validation was conducted over three consecutive series. Calibration standards were prepared at four levels $(k=4)$, and validation standards were prepared at five levels $(k=5)$; each were performed in triplicate $(n=3)$. Due to the high excretion of some steroids in urine, a dilution factor of 10 was tested among the validation standards for DHEAS, AS, EtioS, AG, and EtioG. Calibration curves were built based on the peak area ratios of $5 \alpha \beta \beta$-AdiolG, TG, and DHEAG to TG- $d_{3}$; EG to EG- $d_{3} ; \mathrm{AG}$ and EtioG to $\mathrm{AG}-d_{4}$; TS to TS- $d_{3}$; ES and DHEAS to ES- $d_{3}$; AS to AS- $d 4$; and EtioS to EtioS- $d 5$. The curves were generated over the ranges from 1 to $200 \mathrm{ng} / \mathrm{mL}$ for TS and $\mathrm{ES}$; from 5 to $500 \mathrm{ng} / \mathrm{mL}$ for TG, EG, and DHEAG; from 1 to $500 \mathrm{ng} / \mathrm{mL}$ for $5 \alpha \beta \beta$-AdiolG; from 50 to $3,000 \mathrm{ng} / \mathrm{mL}$ for DHEAS, AS, and EtioS; and from 500 to $8,000 \mathrm{ng} / \mathrm{mL}$ for $\mathrm{AG}$ and EtioG.

Results were expressed in terms of trueness, repeatability, and intermediate precision at each concentration level and were depicted in tolerance profiles for each compound $[37,38]$.

Trueness was defined as the relative bias and was expressed as a percentage of the average recalculated concentrations at each level. Repeatability was considered as the relative standard deviation (RSD) of the averaged intra-day standard deviation to the theoretical value. Finally, intermediate precision was expressed as the RSD of the inter-day standard deviation to the theoretical value.

An external standard calibration with four levels of concentration was used in triplicate to quantify the metabolites in the real-case urine samples.

\section{Carry-over}

The carry-over effect was estimated by injecting an extracted spiked sample at its highest level of concentration (highest calibration standard) for each analyte, followed by three consecutive blank water samples. Peak areas in the extracted samples were considered as $100 \%$, and if a peak was found at the expected retention time in the blank samples, it was expressed as a percentage of the previous sample peak area.

\section{Stability}

Stability of analytes was evaluated by following the EMEA concept paper [33] with four different samples. Samples were either maintained at $+4{ }^{\circ} \mathrm{C}$ or at batch temperature (ca. $+22{ }^{\circ} \mathrm{C}$ ), or they were subjected to three freeze $\left(-20{ }^{\circ} \mathrm{C}\right)$ and thaw (ambient temperature) cycles before analysis, respectively. Finally, an additional sample was prepared for the evaluation of long-term stability at $+4{ }^{\circ} \mathrm{C}$. The time between each analysis was $48 \mathrm{~h}$, except for the long-term stability assay, which was measured after 1 month.

Application to clinical study

Urine samples from a clinical study conducted in 2006 at the Swiss Laboratory for Doping Analyses were analyzed with the method described herein. The clinical study consisted of the oral intake of 12 placebo and 19-norandrostenedione or testosterone undecanoate pills [39]. The pills were composed of $300 \mathrm{mg}$ of mannitol for the placebo group, $80 \mathrm{mg}$ of testosterone undecanoate and $115 \mathrm{mg}$ of mannitol in the testosterone group, and $100 \mathrm{mg}$ of 19-nor-4-androstenedione and $127 \mathrm{mg}$ of mannitol in the 19-norandrostenedione group. The protocol of the study was set as described in Table 1, such that pill intakes occurred three times a week and urine spots were collected in accordance with the study design. Urine samples were split into $20-\mathrm{mL}$ flasks and stored at $-20{ }^{\circ} \mathrm{C}$. For this research, selected samples of both the placebo $(n=7)$ and testosterone $(n=8)$ intake groups were investigated. Amongst the urine specimens, five kinds of samples were studied. However, a t00 sample was determined with the urine collected before any pill intake occurred. Additionally, samples t01 to t05 were taken at 0 , $4,8,24$, and $200 \mathrm{~h}$ after pill intake, respectively. Samples 
Table 1 Design of the clinical study. Pill administrations were performed during the four first weeks. Spot urine samples were collected during the first week, during the second week, on day 24 during the third week and finally on the last day of the study

\begin{tabular}{lllllll}
\hline Week & 1 & 2 & 3 & 4 & 5 & 6 \\
\hline Pill intake/week & 3 & 3 & 3 & 3 & - & - \\
Urine spot & First day & Every day & & $\begin{array}{l}\text { Day 24, } 4 \text { spots } \\
\text { t01 } \rightarrow \text { t04 }\end{array}$ & Last day \\
Sample code & t00 & & t05 & \\
\hline
\end{tabular}

were defrosted at ambient temperature and analyzed. Because the clinical study samples were stocked for 4 years at $-20^{\circ} \mathrm{C}$, five of them were re-analyzed with the GC-MS accredited method (STS 288) to ensure that their stability and validity had been preserved over the intervening years. No significant differences between the measured values for all of the analytes were observed. For the purpose of this study, samples were analyzed by UHPLC-QTOF-MS ${ }^{\mathrm{E}}$ in triplicate, and the analytes were quantified with an external calibration curve. Steroid concentrations were corrected using specific gravity, as was recommended in the WADA technical document [5]. Samples were randomized to avoid batch effect, and a calibration curve was analyzed at the beginning of the sample list and in the middle, to consider the susceptible loss of sensitivity during the batch. One batch constituted 15 samples after triplicate studies and, in addition, a calibration curve of four levels (57 samples) was determined.

\section{Results and discussion}

Method development

\section{$A A S$}

The steroid profile includes the measurement of glucuroand sulfoconjugated T, E, A, Etio, $5 \alpha$-Adiol, and $5 \beta$-Adiol, whose structures are presented in Fig. 1. In regards to the reference population concentration ranges, high sensitivity is required for some of the analytes, such as TG, EG, TS, ES, and DHEAG, because they are normally excreted in low amounts $(0.5$ to $40 \mathrm{ng} / \mathrm{mL})$ in urine. Notably, the only available standard for the $5 \alpha$ - and $5 \beta$-Adiol was the isomer $5 \alpha \beta \beta$-AdiolG, which was a minor metabolite and was excreted in low concentrations $(0.5$ to $10 \mathrm{ng} / \mathrm{mL})$. On the other hand, some analytes are highly excreted in urine, with concentrations reaching $8,000 \mathrm{ng} / \mathrm{mL}$ (AG, EtioG, DHEAS, AS, and EtioS) $[4,7,11]$. Therefore, an analytical method able to extract sulfated and glucuronidated steroids together with selective chromatographic separation to resolve isomers was mandatory.

\section{Sample preparation}

A SPE procedure was developed for conjugated AAS, as it allowed for superior sample clean-up and analyte preconcentration. Oasis HLB cartridges of $30 \mathrm{mg}$ were used to extract simultaneously the sulfated and glucuronidated steroids from the 96-well plate with high sample capacity. A 1-mL volume of the urine specimen was then loaded onto the cartridges with $1 \mathrm{~mL}$ of $2 \%$ formic acid, which ensured constant $\mathrm{pH}$. Two washing steps were successively performed. The first was performed in acidic conditions ( $2 \%$ formic acid), and the second was performed with a
Fig. 1 Structures of the investigated compounds. At the right side of the picture, phase II metabolism enzymes were presented. Uridine diphosphateglucuronosyltransferase (UGT) for glucuronide conjugation and sulfotransferase (SULT) for sulfate conjugation mechanism

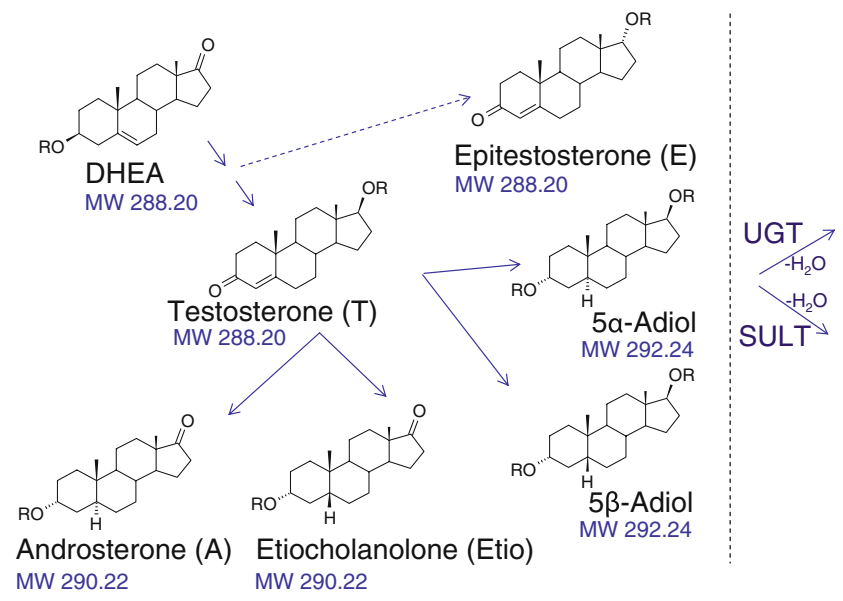


basic solution containing organic solvent $(5 \%$ ammonium hydroxide in methanol, $90 \% / 10 \%, v / v)$. The proportion of methanol was evaluated to avoid the elution of the analytes and was set at a $10 \%$ maximum. Various conditions were also tested for the elution, from $30 \%$ to $95 \%$ methanol. Elution with $40 \%$ methanol was selected, as it allowed the complete recovery of the analytes excreted at low concentration and adjusted the extracted amount for the compounds found at high concentrations in urine, such as DHEAS, which could saturate the QTOF detector equipped with TDC cards. Finally, a preconcentration factor of 10 was obtained, which was necessary to detect and quantify the lowest excreted endogenous AAS. Extraction recoveries (RE) were between $78 \%$ and $137 \%$ for the compounds excreted at low concentrations and between $74 \%$ and $120 \%$ for the high-concentration compounds, as presented in Table 2. Notably, the REs higher than $100 \%$ were attributed to a salting-out effect that could increase the amount extracted in the urine, compared to water, due to the presence of salts, fatty acids, amino acids, or organic bases in urine matrix. As an exception, DHEAS was extracted with REs of $42 \%$ and $49 \%$ at low and high concentrations, respectively. However, as this analyte was observed at a high amount in urine, its detection was not altered. Overall, this method allowed for the simultaneous extraction of the sulfated and glucuronidated steroid from the urine matrix with satisfactory RE.

\section{UHPLC}

Initial UHPLC conditions Various column chemistries, mobile phase compositions, and temperatures were evaluated to obtain the highest possible selectivity between analytes, especially between the different pairs of isomers (TG/EG, TS/ES, AG/EtioG, and AS/EtioS), not resolved by MS. For the stationary phase chemistry screening, specific short columns $(50 \times 2.1 \mathrm{~mm}, 1.7 \mu \mathrm{m})$ of various reversed phase chemistries (e.g., C18, phenyl, and $\mathrm{C} 18$ shield) were selected to evaluate the selectivity in a minimum period of time. Two different mobile phase additives, ammonium formate buffer $(20 \mathrm{mM}$ at $\mathrm{pH} 3.0$ ) and $0.1 \%$ formic acid, were tested. Finally, the column temperature was maintained either at $30{ }^{\circ} \mathrm{C}$ or $50{ }^{\circ} \mathrm{C}$ to assess the influence of this parameter on the selectivity.

However, due to the difficult separation of the isomers, additional combinations of column chemistries, mobile phase additives, and temperatures were tested. To limit the number of conducted experiments, only two gradients $(5 \%$ to $70 \%$ acetonitrile in 8.6 and $26 \mathrm{~min}$ ) were performed, and the retention times were computed on modeling software (Osiris v.4.2, Datalys, Grenoble, France). By modeling the behavior of each compound, the software highlighted the best separation that can be attained with a given condition. For steroids, the best separation of critical pairs of isomers (AS/EtioS and AG/EtioG) was obtained with the Acquity BEH C18 column at a temperature of $50{ }^{\circ} \mathrm{C}$ and with $0.1 \%$ formic acid added to the mobile phase. Nevertheless, the resolution between the most critical pair of isomers, AS and EtioS, was still not sufficient (Rs equal to 0.6) and endogenous interferences from the urine co-eluted with DHEAG, in particular. Therefore, final conditions were performed on a 150 -mm column length to ensure enough selectivity for the quantitative measurement of DHEAG in urine.

Separation optimization To start, an isocratic step was performed with $27 \%$ acetonitrile, and three different

Table 2 Process efficiency, matrix effect, extraction recovery, and extraction yield for the investigated analytes at low and high concentration

\begin{tabular}{|c|c|c|c|c|c|c|c|c|c|c|}
\hline & \multirow{2}{*}{$\begin{array}{l}\text { Low conc. } \\
{[\mathrm{ng} / \mathrm{mL}]}\end{array}$} & \multirow{2}{*}{$\begin{array}{l}\text { High conc. } \\
{[\mathrm{ng} / \mathrm{mL}]}\end{array}$} & \multicolumn{4}{|c|}{ Low concentration } & \multicolumn{4}{|c|}{ High concentration } \\
\hline & & & PE $(\%)$ & ME (\%) & RE (\%) & EY (\%) & PE $(\%)$ & ME (\%) & RE $(\%)$ & EY $(\%)$ \\
\hline$\alpha \beta \beta$-AdiolG & 5 & 200 & 82 & 80 & 103 & 98 & 105 & 92 & 114 & 110 \\
\hline TG & 10 & 200 & 127 & 98 & 130 & 110 & 108 & 91 & 96 & 86 \\
\hline EG & 10 & 200 & 136 & 80 & 137 & 110 & 120 & 105 & 114 & 109 \\
\hline DHEAG & 10 & 200 & 67 & 86 & 78 & 96 & 89 & 95 & 94 & 99 \\
\hline $\mathrm{AG}$ & 1,000 & 4,000 & 111 & 90 & 124 & 92 & 101 & 98 & 103 & 83 \\
\hline EtioG & 1,000 & 4,000 & 109 & 80 & 136 & 97 & 126 & 104 & 120 & 100 \\
\hline TS & 2 & 100 & 122 & 86 & 90 & 67 & 126 & 107 & 118 & 53 \\
\hline ES & 2 & 100 & 101 & 107 & 94 & 106 & 90 & 100 & 90 & 91 \\
\hline DHEAS & 500 & 2,000 & 43 & 102 & 42 & 58 & 70 & 111 & 49 & 74 \\
\hline AS & 500 & 2,000 & 84 & 95 & 89 & 98 & 75 & 102 & 74 & 83 \\
\hline Etios & 500 & 2,000 & 90 & 91 & 99 & 101 & 75 & 91 & 82 & 83 \\
\hline
\end{tabular}


constituents were detected under the peak of DHEAG when extracting the trace at $\mathrm{m} / \mathrm{z} 463.2332 \pm 0.0500 \mathrm{Da}$, corresponding to the theoretical exact mass of deprotonated DHEAG. Here, HPLC modeling software was employed, and the best separation was obtained at $30{ }^{\circ} \mathrm{C}$ with a gradient of $5 \%$ to $37 \%$ acetonitrile over $25 \mathrm{~min}$ and at a flow rate of $300 \mu \mathrm{L} / \mathrm{min}$, as shown in Fig. 2a for the extracted ion DHEAG at $\mathrm{m} / \mathrm{z} 463.23 \pm 0.05 \mathrm{Da}$. However, higher chromatographic resolution was still mandatory for separation between DHEAG and an unknown endogenous compound \#1. In this case, the impact of a lower column temperature was evaluated in a univariate way, and the corresponding chromatograms are presented in Fig. 2b, c. A sufficient separation for all of the analytes was finally obtained at $25{ }^{\circ} \mathrm{C}$. Indeed, when the column was main-
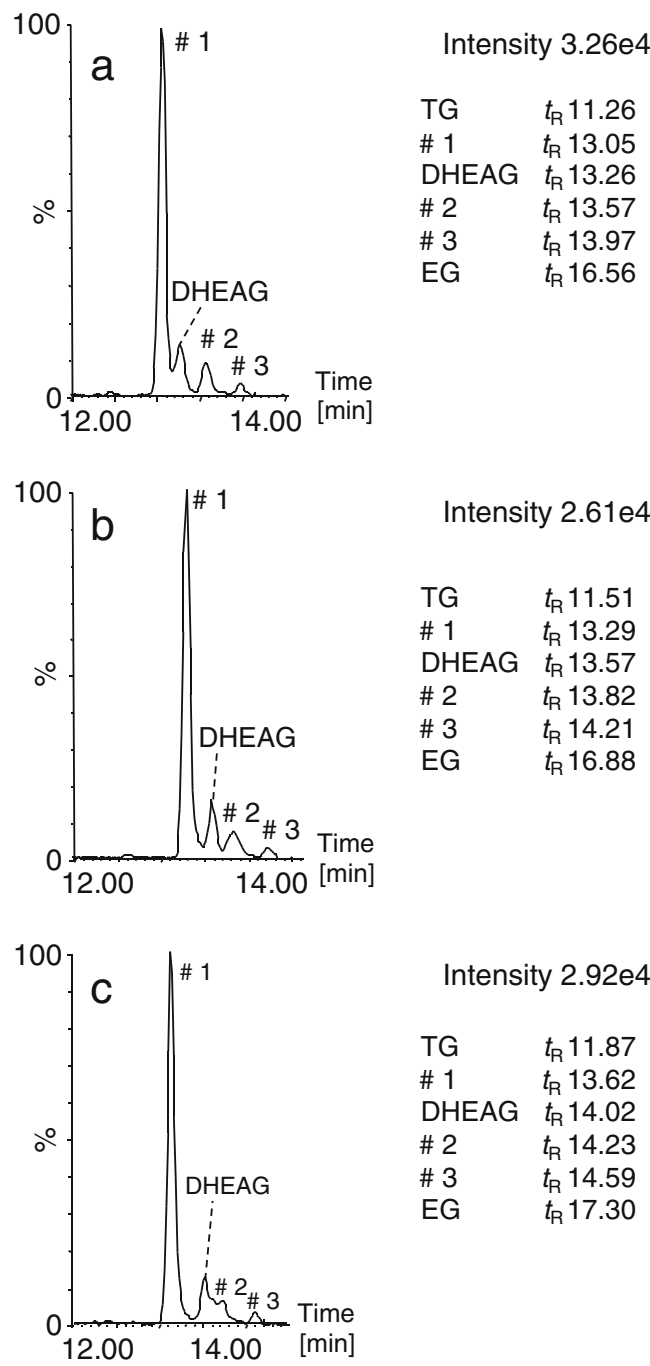

Intensity $2.92 \mathrm{e} 4$

$\begin{array}{ll}\text { TG } & t_{\mathrm{R}} 11.87 \\ \text { \# } 1 & t_{\mathrm{R}} 13.62 \\ \text { DHEAG } & t_{\mathrm{R}} 14.02 \\ \text { \# } 2 & t_{\mathrm{R}} 14.23 \\ \text { \# 3 } & t_{\mathrm{R}} 14.59 \\ \text { EG } & t_{\mathrm{R}} 17.30\end{array}$

Fig. 2 Extracted ion chromatogram (XIC) at $m / z 463.23 \pm 0.05 \mathrm{Da}$ in urine matrix. Chromatographic separation at $300 \mu \mathrm{L} / \mathrm{min}$ with a gradient from $5 \%$ to $37 \%$ acetonitrile over $25 \mathrm{~min}$ at a $30{ }^{\circ} \mathrm{C}$, b $25^{\circ} \mathrm{C}$, and c $20{ }^{\circ} \mathrm{C}$. Peaks \#1, \#2, and \#3 were endogenous isomers of DHEAG tained at $30{ }^{\circ} \mathrm{C}$, compound $\# 1$ was co-eluting with DHEAG, whereas at $20^{\circ} \mathrm{C}$, the peak of the analyte \#2 interfered with DHEAG. The three unknown peaks were most probably isomers of DHEAG.

To summarize, the best conditions to separate the investigated analytes with sufficient selectivity and reasonable analysis time $(36 \mathrm{~min})$ was finally achieved on an Acquity BEH C18 $(150 \times 2.1 \mathrm{~mm}, 1.7 \mu \mathrm{m})$ column, at a temperature of $25{ }^{\circ} \mathrm{C}$, using a gradient from $5 \%$ to $37 \%$ acetonitrile in $25 \mathrm{~min}$, and at a flow rate of $300 \mu \mathrm{L} / \mathrm{min}$.

\section{QTOF-MS}

Both ESI-positive and ESI-negative modes were tested for the ionization of sulfated and glucuronidated steroids. As expected, the highest sensitivity was obtained by analyzing the conjugated steroids as their deprotonated form $[\mathrm{M}-\mathrm{H}]^{-}$ in the negative ESI mode. Specifically, the selectivity obtained by the coupling of the UHPLC to the QTOF-MS is represented in Fig. 3. Here, two chromatograms were extracted from the same analysis to show separately the sulfoconjugated (Fig. 3a) and glucuroconjugated (Fig. 3b) steroids. Notably, the compounds were resolved either by MS or by UHPLC regarding steroid isomers.

For the MS acquisition mode illustrated in Fig. 4a and b for sulfoconjugated and glucuroconjugated DHEA, respectively, $\mathrm{MS}^{\mathrm{E}}$ was selected. It consisted of a first function that was obtained in wide-pass quadrupole mode at a low fixed collision energy $(5 \mathrm{eV})$ and an alternated second function with ramped collision energy from 5 to $70 \mathrm{eV}$. This mode was achieved to obtain maximum information in a single run, with no pre-selection of a precursor ion in the quadrupole.

Specifically, by using ramped collision energy, the deprotonated molecule was maintained, together with the generated fragments. Moreover, as discussed elsewhere [11], the sulfoconjugated steroids had a low fragmentation pattern. The unique ion formed by applying collision energy on the sulfoconjugated steroid was the sulfate moiety itself at $m / z 96.96\left(\mathrm{HSO}_{4}^{-}\right.$; Fig. 4a). The ramped collision energy also yielded more information regarding the fragmentation of glucuroconjugates (Fig. 4b), but they were not specific, as fragments were generated principally from the glucuronic acid itself [13]. For example, the fragment at $\mathrm{m} / \mathrm{z} 287.20$, corresponding to the free steroid (neutral loss of glucuronic acid, $m / z$ 176.03), was found at less than $10 \%$ of the base peak, whereas several fragments of glucuronic acid were also observed $(\mathrm{m} / \mathrm{z}$ 157.02, $\mathrm{m} / \mathrm{z}$ 113.02, $\mathrm{m} / \mathrm{z}$ 85.03, and $\mathrm{m} / \mathrm{z}$ 75.01). The parent and fragment ions obtained for sulfated and glucuronidated steroids are listed in Table 3.

The $\mathrm{MS}^{\mathrm{E}}$ mode was used as an example to gather more information about unknown peaks \#1, \#2, and \#3; the $\mathrm{MS}^{\mathrm{E}}$ 
Fig. 3 UHPLC-QTOF-MS chromatogram (Acquity $\mathrm{BEH} \mathrm{C}_{18}$ $150 \times 2.1 \mathrm{~mm} ; 1.7 \mu \mathrm{m})$ of the investigated analytes. For better readability, the chromatogram was presented in two parts. a The traces corresponded to sulfoconjugated steroids were extracted at $m / z \quad 367.16 \pm 0.05 \mathrm{Da}$ and $369.17 \pm 0.05 \mathrm{Da}$. b The traces from glucuroconjugated steroids were extracted in the chromatogram at $m / z$ 467.26 $0.05 \mathrm{Da}, 463.23 \pm 0.05 \mathrm{Da}$, and $465.24 \pm 0.05 \mathrm{Da}$
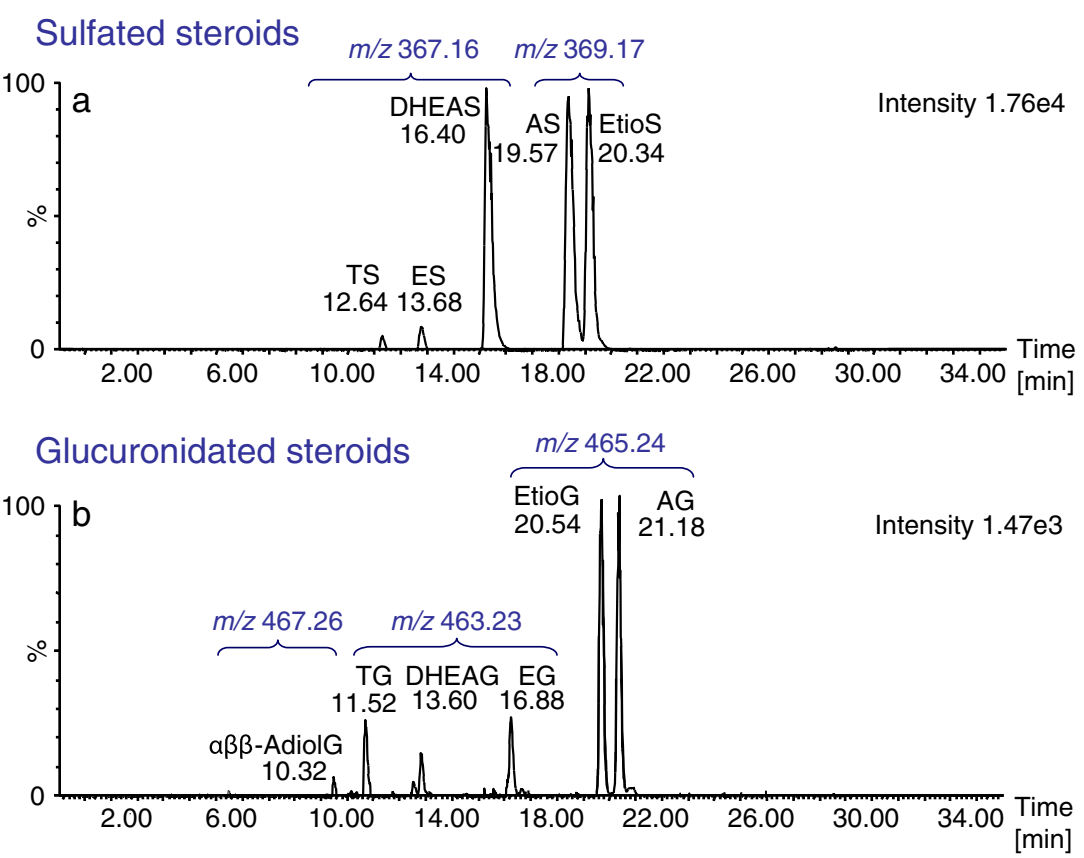

spectra are shown in Fig. 5a-d for each peak. The spectra contained characteristic fragments of DHEAG together with parent and product ions from the co-eluting peaks. However, without selecting a precursor ion, co-eluting peak fragments obtained in the spectra were also viewed. In these cases, we linked a precursor ion to its product ions by use of retention time information and known mass defect (glucuronide, sulfate, or water loss). Another way to determine this relationship between the ions could also be automatically establish by a dedicated software. As observed in Fig. 5a, ions corresponding to peak \#1 were the parent ion at $\mathrm{m} / \mathrm{z} 463.23$ and fragment ions at $m / z 287.20, \mathrm{~m} / z$ 157.02, $\mathrm{m} / \mathrm{z}$ 113.02, $m / z 85.03$, and $m / z$ 75.01. These ions are common to a glucuronide conjugate, as reported in Table 3. However, interfering ions at $\mathrm{m} / \mathrm{z} 367.15$ and 96.96, corresponding to a sulfoconjugated steroid and to the inorganic hydrogenosulfate $\left(\mathrm{HSO}_{4}{ }^{-}\right)$, respectively, were also present in the spectrum, due to nonselective fragmentation. For further confirmations, MS/MS experiments were conducted on each peak with selection of the parent ion $(\mathrm{m} / \mathrm{z} 463.23)$ as the precursor ion for fragmentation at a fixed collision energy of $25 \mathrm{eV}$ (data not shown). The same fragments were obtained with MS/MS and $\mathrm{MS}^{\mathrm{E}}$ acquisition modes by selecting either the $\mathrm{m} / \mathrm{z}$ 463.23 precursor ion or by applying the nonselective ramped collision energy. The advantages of $\mathrm{MS}^{\mathrm{E}}$ over MS/MS acquisition mode were the nonselective approach allowing detection and characterization of new entities in metabolite studies, as all data were collected in exact mass mode. Moreover, the information provided by the QTOF-MS ${ }^{\mathrm{E}}$ acquisition was particularly relevant for biological matrices, as data could be processed retroactively.
Validation of the study

\section{Selectivity}

An additional experiment was previously performed to improve resolution by injecting the analytes extracted in the matrix on a $300-\mathrm{mm}$ column length. Here, two $150-\mathrm{mm}$ columns were connected in series, and the optimized method was transferred geometrically by adjusting the injection volume $(40 \mu \mathrm{L})$ and the gradient profile ( $5 \%$ to $37 \%$ acetonitrile in $83.9 \mathrm{~min})$. Furthermore, the flow rate was reduced $(180 \mu \mathrm{L} / \mathrm{min})$ to reach a backpressure compatible with the system. Overall, no interfering peaks were observed in the extracted MS traces for all analytes.

As the investigated analytes are endogenous compounds, selectivity was evaluated by the quantitative analysis of six independent adult urine samples, and the results were compared to the GC-MS accredited method measurements. For the 11 analytes, the results obtained were not significantly different than those obtained by GC-MS, suggesting no over- or underestimation. Moreover, the $\mathrm{MS}^{\mathrm{E}}$ acquisition mode allowed for the enhancement of the selectivity. Specifically, the combined information of the molecular ion with the fragmentation pattern obtained in the second function allowed for specific confirmation ions. The selectivity was also estimated by comparing I.S.s spiked in negative children's urine specimens to adult urine specimens. For each I.S., no co-elution was observed at the selected retention time and $m / z$ window. 
Fig. 4 UHPLC-QTOF-MS ${ }^{\mathrm{E}}$ acquisition mode. a In the first function obtained at low collision energy $(5 \mathrm{eV})$, the molecular ion of DHEAS is shown at $\mathrm{m} / \mathrm{z} 367.16$, while the sulfate moiety fragment at $\mathrm{m} / \mathrm{z}$ 96.96, together with the molecular ion, is obtained in the second function with ramped energy from 5 to $70 \mathrm{eV}$.

b Spectra at low and ramped energy were obtained from the peak trace of DHEAG. The molecular ion was found in the first function at $m / z$ 463.23. A fragmentation pattern was obtained in the second function with ions at $\mathrm{m} / \mathrm{z} 287.20, \mathrm{~m} / \mathrm{z}$ 157.01, $\mathrm{m} / \mathrm{z} 113.02, \mathrm{~m} / \mathrm{z} 85.03$, $\mathrm{m} / \mathrm{z} 75.01$, and $\mathrm{m} / \mathrm{z} 71.02$, together with the molecular ion at $\mathrm{m} / \mathrm{z} 463.23$

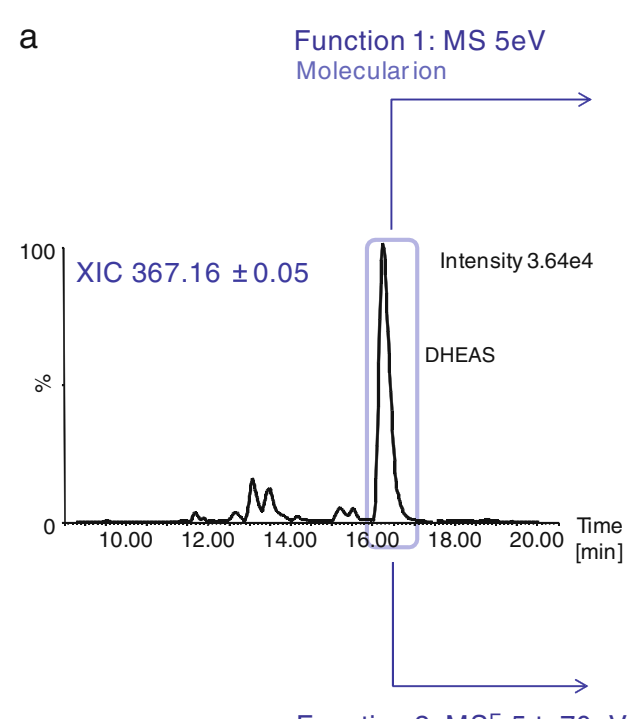

Function 2: MSE 5 to70eV Molecularion and fragments
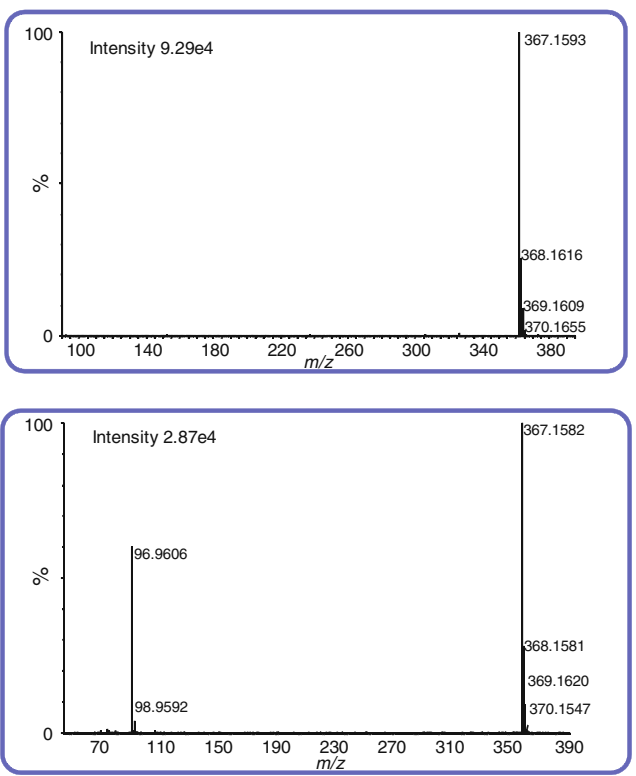

b
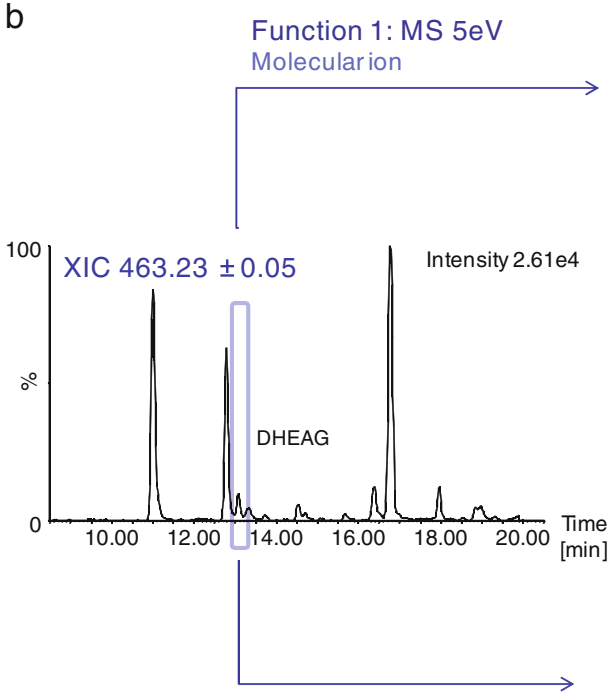

Function 2: MSE 5 to70eV Molecular ion and fragments
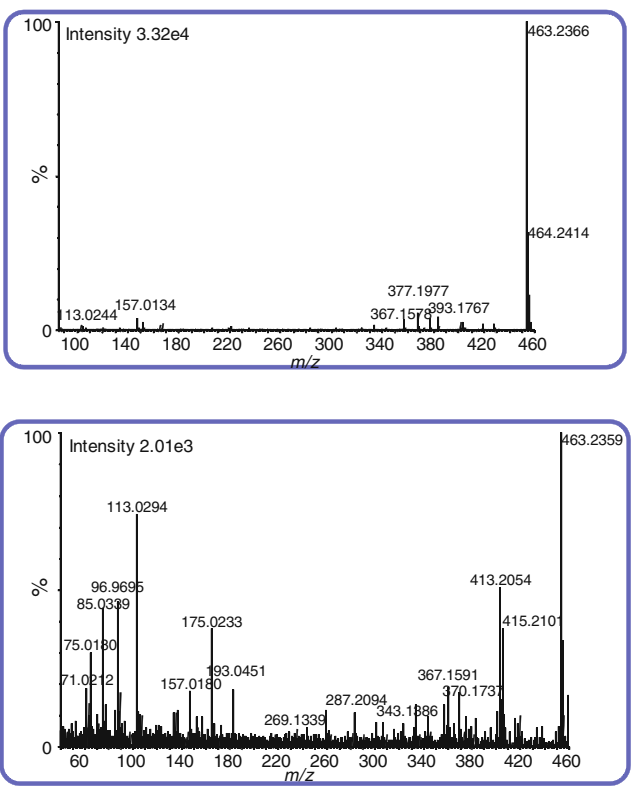

\section{Matrix effects}

The ME were measured on the basis of experiments described by Matuszewski et al. [35] and classified according to the method described by Marchi et al. [36] in case of SPE prior to LC-MS. The measured PE, ME, RE, and EY, at low and high concentrations, are presented in Table 2. PE was considered suitable for quantitative analysis, and ME reflected no ion suppression or enhancement effect with values between $80 \%$ and $111 \%$ at low and high concentrations. Additionally, REs were satisfactory for all of the analytes, as a salting-out effect, due to the presence of the matrix, enhanced the detection of most analytes at low concentrations, except for DHEAS, which was extracted with less than $50 \%$ at both concentrations.
However, as discussed before, this compound was excreted at a high concentration, so that the loss during the extraction step was not detrimental to its sensitivity. Lastly, EY was good, with values near $100 \%$ for all analytes except for TS and DHEAS. For these compounds, EY was lower than $70 \%$ and $80 \%$, respectively, but it was considered sufficient to detect them at low concentrations.

\section{Quantitative analysis}

Results of the validation assays were built into a tolerance profile for each compound with a $\beta$-value of $80 \%$, as shown in Fig. 6, and the investigated parameters are reported in Table 4. As recommended elsewhere [31], a variability of $30 \%$ was found to be acceptable for the quantification of 
Table 3 Parent and fragment ion assignment for glucuronidated and sulfated phase II metabolites of testosterone

\begin{tabular}{|c|c|c|c|c|c|}
\hline & Compounds & Deprotonated molecule & $m / z$ & Fragments & $m / z$ \\
\hline Sulfated steroids & $\begin{array}{l}\text { AS, EtioS } \\
\text { TS, ES, DHEAS }\end{array}$ & $\begin{array}{l}{[\mathrm{M}-\mathrm{H}]^{-}} \\
{[\mathrm{M}-\mathrm{H}]^{-}}\end{array}$ & $\begin{array}{l}369.17 \\
367.16\end{array}$ & {$\left[\mathrm{HSo}_{4}\right]^{-}$} & 96.96 \\
\hline \multirow[t]{12}{*}{ Glucuronidated steroids } & \multirow[t]{2}{*}{ AG, EtioG } & \multirow[t]{2}{*}[\mathrm{M}-\mathrm{H}]{$^{-}$} & \multirow[t]{2}{*}{465.24} & {$\left[\mathrm{M}-\mathrm{H}-\mathrm{H}_{2} \mathrm{O}\right]^{-}$} & 447.23 \\
\hline & & & & {$[\mathrm{M}-\mathrm{H}-\mathrm{Gluc}]^{-}$} & 289.20 \\
\hline & \multirow[t]{2}{*}{$\alpha \beta \beta$-AdiolG } & \multirow[t]{2}{*}[\mathrm{M}-\mathrm{H}]{$^{-}$} & \multirow[t]{2}{*}{467.26} & {$\left[\mathrm{M}-\mathrm{H}-\mathrm{H}_{2} \mathrm{O}\right]^{-}$} & 449.25 \\
\hline & & & & {$[\mathrm{M}-\mathrm{H}-\mathrm{Gluc}]^{-}$} & 291.21 \\
\hline & \multirow[t]{2}{*}{ TG, EG, DHEAG } & \multirow[t]{2}{*}[\mathrm{M}-\mathrm{H}]{$^{-}$} & \multirow[t]{8}{*}{463.23} & {$\left[\mathrm{M}-\mathrm{H}-\mathrm{H}_{2} \mathrm{O}\right]^{-}$} & 445.22 \\
\hline & & & & {$[\mathrm{M}-\mathrm{H}-\mathrm{Gluc}]^{-}$} & 287.20 \\
\hline & \multirow{6}{*}{\multicolumn{2}{|c|}{ Common fragmentation to all glucuonides }} & & {$[\text { Gluc- }-\mathrm{H}]^{-}$} & 175.02 \\
\hline & & & & {$\left[\text { Gluc }-\mathrm{H}-\mathrm{H}_{2} \mathrm{O}\right]^{-}$} & 157.01 \\
\hline & & & & [Gluc- $\left.-\mathrm{H}-\mathrm{H}_{2} \mathrm{O}-\mathrm{CO}_{2}\right]^{-}$ & 113.02 \\
\hline & & & & {$[\mathrm{Glu}-?]^{-}$} & 85.03 \\
\hline & & & & {$[\mathrm{Glu}-?]^{-}$} & 75.01 \\
\hline & & & & {$[\mathrm{Glu}-?]^{-}$} & 71.02 \\
\hline
\end{tabular}

these steroids in urine. Additionally, for the calibration, a linear regression was obtained after $1 / x$-weighting for each analyte.

Trueness, repeatability, and intermediate precision were found to be acceptable over the validated range for the majority of compounds, as shown in Table 4. However, the lower limit of quantification was estimated from the absolute tolerance profile at 2, 4, and $5 \mathrm{ng} / \mathrm{mL}$ for TS, ES, and $5 \alpha \beta \beta$-AdiolG, respectively, instead of $1 \mathrm{ng} / \mathrm{mL}$, as
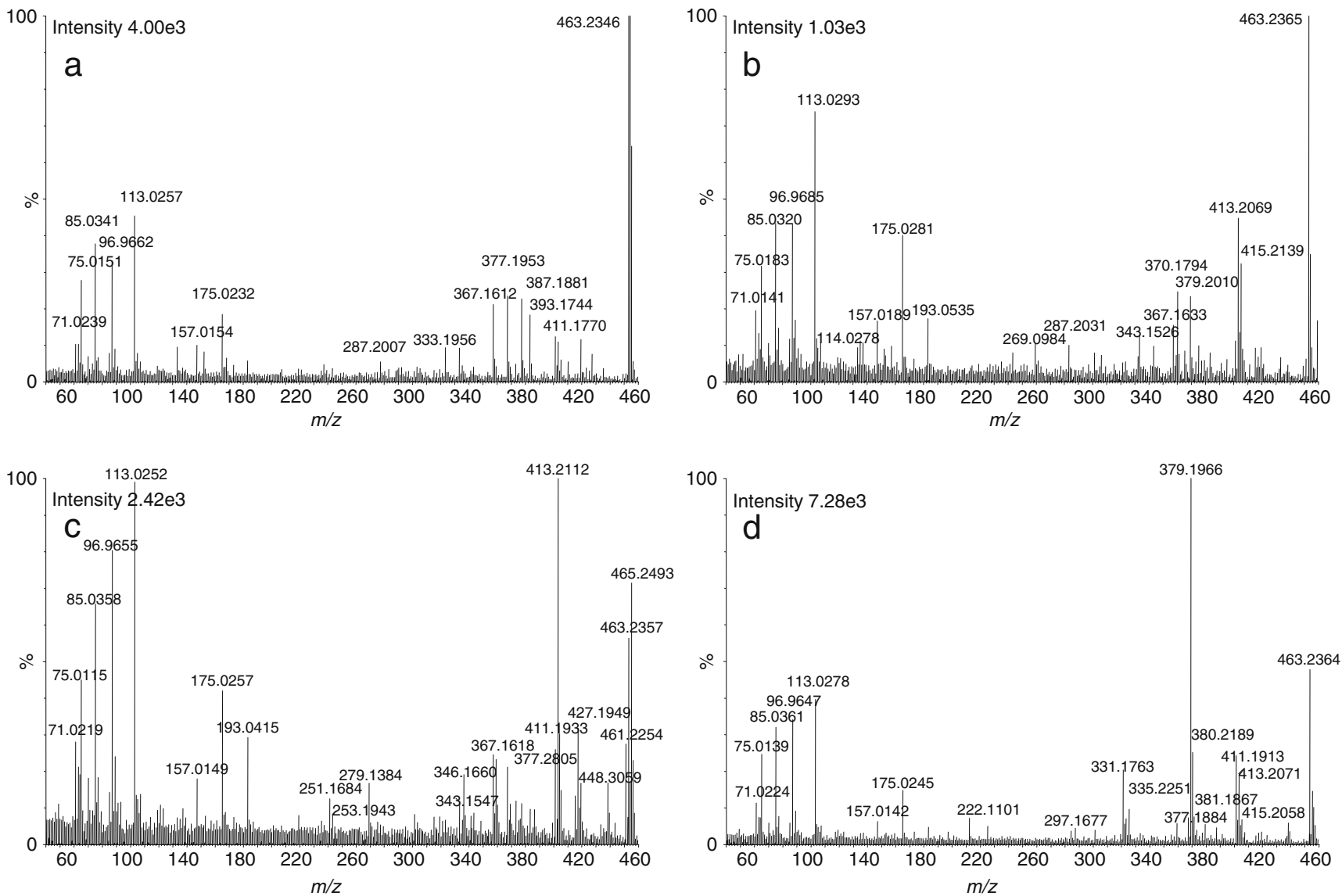

Fig. $5 \mathrm{MS}^{\mathrm{E}}$ spectra of a peak \#1 $\left(t_{\mathrm{R}}, 13.29\right)$, b DHEAG $\left(t_{\mathrm{R}}, 13.57\right)$, c peak \#2 $\left(t_{\mathrm{R}}, 13.82\right)$, and $\mathbf{d}$ peak \#3 $\left(t_{\mathrm{R}}, 14.21\right)$ obtained in the second function with ramped energy from 5 to $70 \mathrm{eV}$ 

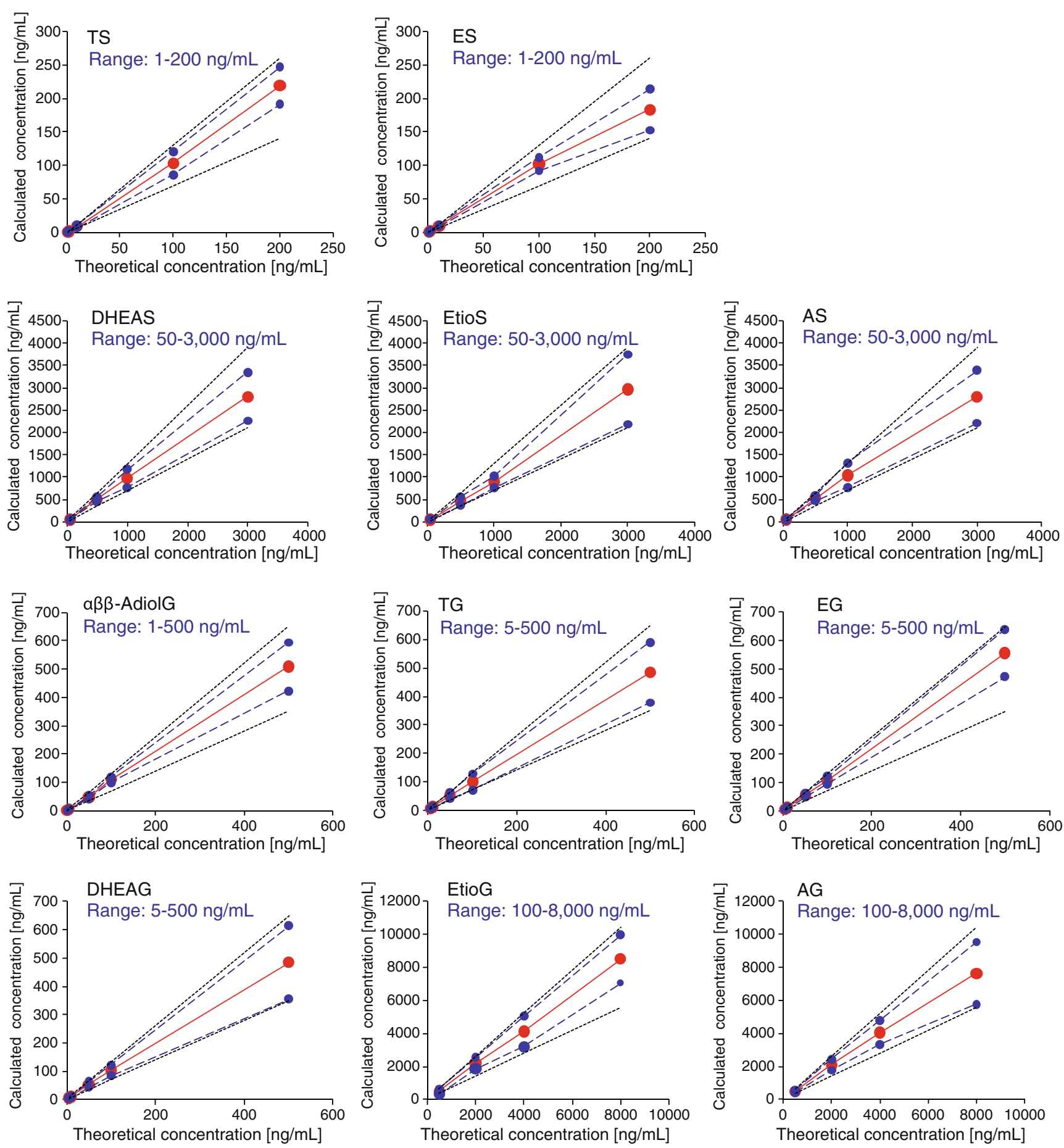

Fig. 6 Absolute tolerance profile for the investigated analytes with a $\beta$-expectation of $80 \%$. Solid line corresponded to theoretical value, dashed line to the confidence interval, and dotted line to the acceptability $(30 \%)$

the repeatability and intermediate precision were above $30 \%$. The tenfold dilution factor for the four analytes excreted in urine at high amounts (AS, EtioS, AG, and EtioG) was also validated. However, it is notable that, at the lower limit of quantification (LLOQ), the number of points per peak was estimated at a minimum of 30 , which was sufficient for the quantitative analysis, because it took into account the $\mathrm{MS}^{\mathrm{E}}$-ramped collision energy function and the DRE lockmass function. The method was thus considered adequate for the determination of endogenous sulfated and glucuronidated steroids in urine. 
Table 4 Validation parameters for the 11 investigated steroids

\begin{tabular}{|c|c|c|c|c|c|c|}
\hline Compounds & Concentrations $[\mathrm{ng} / \mathrm{mL}]$ & Trueness $(\%)$ & Repeatability (\%) & Intermediate precision (\%) & LLOQ [ng/mL] & $\mathrm{LOD}[\mathrm{ng} / \mathrm{mL}]$ \\
\hline \multirow[t]{5}{*}{ TS } & 1 & 97 & 28.4 & 47.6 & 2 & 1.0 \\
\hline & 2 & 102 & 17.1 & 17.8 & & \\
\hline & 10 & 96 & 8.3 & 13.1 & & \\
\hline & 100 & 104 & 11.4 & 12.1 & & \\
\hline & 200 & 109 & 4.2 & 8.9 & & \\
\hline \multirow[t]{5}{*}{ ES } & 1 & 100 & 17.8 & 29.8 & 4 & 1.0 \\
\hline & 2 & 116 & 21.4 & 22.7 & & \\
\hline & 10 & 101 & 8.9 & 10.5 & & \\
\hline & 100 & 102 & 3.6 & 6.8 & & \\
\hline & 200 & 92 & 9.1 & 10.7 & & \\
\hline \multirow[t]{5}{*}{ DHEAS } & 50 & 97 & 13.3 & 13.1 & 50 & 1.0 \\
\hline & 500 & 102 & 7.5 & 7.6 & & \\
\hline & 1,000 & 97 & 8.5 & 11.6 & & \\
\hline & 3,000 & 93 & 8.0 & 12.2 & & \\
\hline & $30,000 / 10$ & 119 & 17.8 & 17.5 & & \\
\hline \multirow[t]{5}{*}{ AS } & 50 & 108 & 20.9 & 21.6 & 50 & 1.0 \\
\hline & 500 & 106 & 4.1 & 7.7 & & \\
\hline & 1,000 & 104 & 9.8 & 15.0 & & \\
\hline & 3,000 & 93 & 7.6 & 13.1 & & \\
\hline & $30,000 / 10$ & 91 & 5.9 & 12.8 & & \\
\hline \multirow[t]{5}{*}{ EtioS } & 50 & 108 & 9.1 & 10.2 & 50 & 1.0 \\
\hline & 500 & 93 & 7.6 & 11.6 & & \\
\hline & 1,000 & 89 & 5.0 & 7.3 & & \\
\hline & 3,000 & 99 & 17.7 & 18.3 & & \\
\hline & $30,000 / 10$ & 88 & 4.5 & 10.3 & & \\
\hline \multirow[t]{5}{*}{$\alpha \beta \beta$-AdiolG } & 1 & 125 & 70.1 & 76.0 & 5 & 1.0 \\
\hline & 5 & 102 & 9.9 & 8.5 & & \\
\hline & 50 & 96 & 6.3 & 7.3 & & \\
\hline & 100 & 110 & 8.4 & 8.0 & & \\
\hline & 500 & 102 & 12.9 & 12.0 & & \\
\hline \multirow[t]{5}{*}{ TG } & 5 & 86 & 16.3 & 18.9 & 5 & 1.0 \\
\hline & 10 & 100 & 13.3 & 14.1 & & \\
\hline & 50 & 102 & 10.6 & 13.2 & & \\
\hline & 100 & 99 & 16.1 & 15.9 & & \\
\hline & 500 & 97 & 3.8 & 11.9 & & \\
\hline \multirow[t]{5}{*}{ EG } & 5 & 93 & 15.1 & 16.3 & 5 & 1.0 \\
\hline & 10 & 104 & 7.8 & 13.8 & & \\
\hline & 50 & 110 & 4.1 & 7.0 & & \\
\hline & 100 & 108 & 3.8 & 8.4 & & \\
\hline & 500 & 111 & 10.7 & 11.7 & & \\
\hline \multirow[t]{5}{*}{ DHEAG } & 5 & 109 & 14.7 & 16.9 & 5 & 1.0 \\
\hline & 10 & 100 & 9.0 & 11.6 & & \\
\hline & 50 & 106 & 10.3 & 11.8 & & \\
\hline & 100 & 103 & 7.6 & 10.2 & & \\
\hline & 500 & 97 & 12.5 & 14.4 & & \\
\hline \multirow[t]{4}{*}{$\mathrm{AG}$} & 500 & 100 & 10.1 & 10.5 & 500 & 5 \\
\hline & 2,000 & 105 & 5.4 & 10.0 & & \\
\hline & 4,000 & 101 & 8.0 & 10.6 & & \\
\hline & 8,000 & 95 & 7.6 & 15.3 & & \\
\hline
\end{tabular}


Table 4 (continued)

\begin{tabular}{|c|c|c|c|c|c|c|}
\hline Compounds & Concentrations $[\mathrm{ng} / \mathrm{mL}]$ & Trueness $(\%)$ & Repeatability (\%) & Intermediate precision $(\%)$ & LLOQ [ng/mL] & $\mathrm{LOD}[\mathrm{ng} / \mathrm{mL}]$ \\
\hline & $80,000 / 10$ & 98 & 4.1 & 4.6 & & \\
\hline \multirow[t]{5}{*}{ EtioG } & 500 & 99 & 17.5 & 21.2 & 500 & 5 \\
\hline & 2,000 & 105 & 4.8 & 5.4 & & \\
\hline & 4,000 & 100 & 13.8 & 13.4 & & \\
\hline & 8,000 & 105 & 11.9 & 13.7 & & \\
\hline & $80,000 / 10$ & 95 & 7.2 & 10.5 & & \\
\hline
\end{tabular}

\section{Carry-over}

The carry-over effect at the injection step was determined by analyzing a water blank sample directly after the highest level standard calibration. No peak was found in the subsequent blank samples, except for EtioG and AG, for which only $0.02 \%$ and $0.01 \%$, respectively, of the former peak was detected in the first blank sample. In other words, the carry-over effect was found to be negligible for all analytes.

\section{Stability}

Stability assays were performed at a concentration of $5 \mathrm{ng} / \mathrm{mL}$ for TS and ES; at $10 \mathrm{ng} / \mathrm{mL}$ for $5 \alpha \beta \beta$-AdiolG, TG, EG, and DHEAG; at $200 \mathrm{ng} / \mathrm{mL}$ for $\mathrm{AS}$, EtioS, and DHEAS; and at $1,000 \mathrm{ng} / \mathrm{mL}$ for EtioG and AG. Stability was evaluated on three measurements separated by $48 \mathrm{~h}$ in three storage conditions as follows: at $+4{ }^{\circ} \mathrm{C}$ (autosampler condition), at room temperature $\left(+22{ }^{\circ} \mathrm{C}\right)$, and after three freeze-thaw cycles (freezing at $-20{ }^{\circ} \mathrm{C}$ and thawing at room temperature). All of these conditions did not affect the stability of the analytes with relative standard deviations (RSD) below 15\% (data not shown). However, after maintaining the analytes at $+4{ }^{\circ} \mathrm{C}$ for 1 month in the matrix, sample degradation was observed with RSD rising to $27 \%$ for DHEAG. Analytes loss was estimated to be around $30 \%$ of the initial peak area. Consequently, samples shall not be conserved more than 6 days (three times $48 \mathrm{~h}$ ) before analysis at $+22{ }^{\circ} \mathrm{C}$ or $+4{ }^{\circ} \mathrm{C}$.

\section{Application to clinical study}

The 100 samples from a clinical study were analyzed to determine the levels of glucuronidated and sulfated steroids. UHPLC-QTOF-MS results were compared with values obtained by GC-MS for the glucuroconjugates and by LC$\mathrm{MS} / \mathrm{MS}$ for the sulfoconjugates, with a method presented elsewhere [11]. The Bland-Altman approach was used to further assess the differences between the methods. Quantitative measurements obtained by UHPLC-QTOF-MS were in agreement with those performed by GC-MS and LC-MS/
MS, as the statistical Bland-Altman test showed no significant difference with a risk $\alpha$ of 0.05 .

All well-known parameters influenced by testosterone administration were modified, in terms of ratio or individual levels, as already described by Baume et al. [40]. For the majority of subjects $(n=6)$, an enhancement of the T/E value, together with $\mathrm{TG}, \mathrm{AG}$, and EtioG concentrations, was observed from point $+4 \mathrm{~h}$ ( $\mathrm{t} 02)$ to point $+8 \mathrm{~h}$ (t03) after testosterone administration. However, for two subjects among the eight who had taken $80 \mathrm{mg}$ of testosterone, no particular change in concentration or ratio was observed. One athlete was detected to have a deficient genotype in the UGT2B17 gene, causing significantly lower excretion of TG in urine [41], and the other was considered as a fast excretor, with an excretion peak and return to basal state before t02. Overall, the detection window based on glucuronidated steroids was short and not very sensitive, as two individuals out of eight were not detected. The first hypothesis was to observe sulfated metabolites by considering the fact that if a deletion was present on the glucuroconjugation enzyme, sulfoconjugation could compensate for steroid elimination. However, the concentration of the inorganic sulfate substrate for the enzyme sulfate transferase could be the limiting factor [42], and further investigation should be performed on sulfoconjugated metabolism.

As analyses were acquired in the QTOF-MS ${ }^{\mathrm{E}}$ mode, rich information was provided by combining exact mass measurements over the mass. This opened the way to a broader steroid profile with chemometric tools for data treatment to highlight minor metabolites or new steroid entities influenced by an oral intake of testosterone.

\section{Conclusion}

Direct analysis of steroid metabolism comprising phase II metabolites is still challenging because these compounds are not restricted to professional sport and can be used as biomarkers of diseases related to steroid secretion.

A UHPLC-QTOF-MS ${ }^{\mathrm{E}}$ method was validated and allowed for the quantification of glucuronidated and 
sulfated steroids within the same analysis. Thanks to UHPLC resolution, critical pairs of isomers can be separated. The sample preparation was performed on Oasis HLB SPE cartridges and allowed for a superior sample clean-up and ten-fold pre-concentration of analytes. The chromatographic analysis time required to separate targeted analytes was $36 \mathrm{~min}$ (including the re-equilibration time) on a $150-\mathrm{mm}$ column length. An optimal gradient time was mandatory to obtain the needed selectivity between the investigated analytes and the potentially interfering compounds present in the matrix. Indeed, as the sample preparation was generic towards the class of conjugated steroids present in the urine, numerous steroid phase II metabolites were extracted with the targeted compounds. However, these compounds can also be used as biomarkers of steroid administration within the framework of a clinical study. By combining information obtained with QTOF-MS ${ }^{\mathrm{E}}$ acquisition mode and with chemometric tools, additional perspectives on this work could be expected. Furthermore, this method opens a promising route to a broader understanding of steroid profile (steroidomics), including sulfoconjugated metabolites, and to the discovery of potentially important indirect biomarkers for the detection of exogenous testosterone misuse, which will be published elsewhere.

\section{References}

1. Mareck U, Geyer H, Opfermann G, Thevis M, Schänzer W (2008) J Mass Spectrom 43:877-891

2. Taylor NF (2006) Methods Mol Biol 324:159-175

3. Sjöqvist F, Garle M, Rane A (2008) Lancet 371:1872-1882

4. Van Renterghem P, Van Eenoo P, Delbeke FT (2010) Steroids 75:1047-1057

5. World Anti-doping Agency (WADA) (2010) The world anti-doping code. Endogenous anabolic androgenic steroids, testing and reporting guidance, technical document TD2010EAAS, Montreal. Available at http://www.wada-ama.org. Accessed on Dec 2010

6. Ayotte C (2009) Detecting the administration of endogenous anabolic androgenic steroids. In: Thieme D, Hemmersbach P (ed) Doping in sports: biochemical principles, effects and analysis. Springer, Heidelberg, pp 77-98

7. Van Renterghem P, Van Eenoo P, Geyer H, Schänzer W, Delbeke FT (2011) Steroids 75:154-163

8. Bowers LD (1997) Clin Chem 43:1299-1304

9. Bowers LD, Sanaullah (1996) J Chromatogr B Biomed Sci Appl $87: 61-68$

10. Antignac J-P, Brosseaud A, Gaudin-Hirret I, André F, Bizec BL (2005) Steroids 70:205-216

11. Strahm E, Kohler I, Rudaz S, Martel S, Carrupt P-A, Veuthey J-L, Saugy M, Saudan C (2008) J Chromatogr A 1196-1197:153-160

12. Bean KA, Henion JD (1997) J Chromatogr B Biomed Sci Appl 690:65-75

13. Buiarelli F, Coccioli F, Merolle M, Neri B, Terracciano A (2004) Anal Chim Acta 526:113-120

14. Pozo OJ, Van Eenoo P, Van Thuyne W, Deventer K, Delbeke FT (2008) J Chromatogr A 1183:108-118

15. Flores-Valverde AM, Hill EM (2008) Anal Chem 80:8771-8779
16. Rijk JCW, Lommen A, Essers ML, Groot MJ, Van Hende JM, Doeswijk TG, Nielen MWF (2009) Anal Chem 81:6879-6888

17. Guillarme D, Ruta J, Rudaz S, Veuthey J-L (2009) Anal Bioanal Chem 397:1069-1082

18. Hopfgartner G, Bourgogne E (2003) Mass Spectrom Rev 22:195-214

19. Georgakopoulos CG, Vonaparti A, Stamou M, Kiousi P, Lyris E, Angelis YS, Tsoupras G, Wuest B, Nielen MWF, Panderi I, Koupparis M (2007) Rapid Commun Mass Spectrom 21:24392446

20. Fragkaki AG, Tsantili-Kakoulidou A, Angelis YS, Koupparis M, Georgakopoulos C (2009) J Chromatogr A 1216:8404-8420

21. Galesio M, Rial-Otero R, Capelo-Martínez JL (2009) Rapid Commun Mass Spectrom 23:1783-1791

22. Peters RJB, Rijk JCW, Bovee TFH, Nijrolder AWJM, Lommen A, Nielen MWF (2010) Anal Chim Acta 664:77-88

23. Nielen MWF, Bovee TFH, van Engelen MC, Rutgers P, Hamers ARM, van Rhijn JA, Hoogenboom LAP (2005) Anal Chem 78:424-431

24. Temesi DG, Martin S, Smith R, Jones C, Middleton B (2010) Rapid Commun Mass Spectrom 24:1730-1736

25. Plumb RS, Johnson KA, Rainville P, Smith BW, Wilson ID, Castro-Perez JM, Nicholson JK (2006) Rapid Commun Mass Spectrom 20:1989-1994

26. Purves RW, Gabryelski W, Li L (1998) Rapid Commun Mass Spectrom 12:695-700

27. Zhang H, Heinig K, Henion J (2000) J Mass Spectrom 35:423-431

28. Zhang N, Fountain ST, Bi H, Rossi DT (2000) Anal Chem 72:800-806

29. World Anti-Doping Agency (WAA) (2010) International standard for laboratories V5.0. Available at http:/www.wada-ama.org. Accessed on Dec 2010

30. International Conference on Harmonisation of Technical Requirements for Registration of Pharmaceuticals for Human Use (2005) ICH harmonised tripartite guideline, validation of analytical procedures: text and methodology, Q2 (R1). ICH, Geneva

31. Food and Drug Administration (2001) Guidance for industry: bioanalytical method validation. US Department of Health and Human Services, FDA, Centre for Drug Evaluation and Research, Rockville

32. Viswanathan C, Bansal S, Booth B, DeStefano A, Rose M, Sailstad J, Shah V, Skelly J, Swann P, Weiner R (2007) AAPS J 9: E30-E42

33. European Medicines Agency, Committee for Medicinal Products for Human Use (CHMP) (2008) Concept paper/recommendations on the need for a (CHMP) guideline on the validation of bioanalytical methods, London, 18 Dec

34. Weykamp CW, Penders TJ, Schmidt NA, Borburgh AJ, van de Calseyde JF, Wolthers BJ (1989) Clin Chem 35:2281-2284

35. Matuszewski BK, Constanzer ML, Chavez-Eng CM (2003) Anal Chem 75:3019-3030

36. Marchi I, Viette V, Badoud F, Fathi M, Saugy M, Rudaz S, Veuthey J-L (2010) J Chromatogr A 1217:4071-4078

37. Rozet E, Ceccato A, Hubert C, Ziemons E, Oprean R, Rudaz S, Boulanger B, Hubert P (2007) J Chromatogr A 1158:111-125

38. Feinberg M, Boulanger B, Dewé W, Hubert P (2004) Anal Bioanal Chem 380:502-514

39. Baume N, Schumacher Y, Sottas P-E, Bagutti C, Cauderay M, Mangin P, Saugy M (2006) Eur J Appl Physiol 98:329-340

40. Baume N, Saudan C, Desmarchelier A, Strahm E, Sottas P-E, Bagutti C, Cauderay M, Schumacher YO, Mangin P, Saugy M (2006) Steroids 71:364-370

41. Strahm E, Sottas PE, Schweizer C, Saugy M, Dvorak J, Saudan C (2009) Br J Sports Med 43:1126-1130

42. Weinshilboum R, Otterness D (1994) Sulfotransferase enzymes. In: Kauffmann FC (ed) Conjugation-deconjugation reactions in drug metabolism and toxicity. Springer, Berlin, pp 45-78 